\title{
Ausência de recursos ou adaptação ao ambiente? Uma análise dos riscos estratégicos sob a perspectiva das forças de mercado versus competências dinâmicas na pequena empresa
}

\author{
Lack of resources or adaptation to the environment? An analysis of strategic risks \\ in the perspective of market forces versus capability dynamic in small business
}

Juliana Cândido Custódio[a], Eduardo Damião da Silva ${ }^{[\mathrm{b}]}$

[a] Doutoranda em Administração pelo Programa de Pós-Graduação em Administração da Pontifícia Universidade Católica do Paraná, Curitiba, PR - Brasil, e-mail: juliana.custodio@pucpr.br

[b] Professor titular do Programa de Pós-Graduação em Administração da Pontifícia Universidade Católica do Paraná, Curitiba, PR - Brasil, e-mail: eduardo.damiao@pucpr.br

\section{Resumo}

A vantagem competitiva da pequena empresa pode ser criada por diferentes perspectivas, dentre as quais são evidenciadas as estratégias baseadas nas forças de mercado e as estratégias baseadas nos recursos e capacidades específicas da organização. Nas pequenas empresas nota-se que há maior ênfase na criação de estratégias fundamentadas nas forças de mercado, mesmo que pela utilização desta perspectiva, possa ser diminuída a competitividade da empresa. Portanto, o objetivo deste estudo é entender como surgem e quais são os riscos provenientes da formulação da estratégia competitiva na pequena empresa sob a perspectiva da exploração das forças de mercado em detrimento da perspectiva das competências dinâmicas. Para tanto, foi utilizado um estudo de caso em uma pequena empresa de varejo de Curitiba, que propiciou a verificação da concepção das estratégias formuladas na pequena empresa e os riscos a elas associadas. Na primeira fase do estudo, os dados foram coletados por meio de entrevistas em profundidade e observação, e analisados conforme análise de conteúdo. Para verificação dos riscos estratégicos foi elaborado um mapa cognitivo para identificação de riscos e aplicada uma adaptação do modelo Brasiliano (2006) para mensuração e análise de riscos. Foi verificado que diante da principal perspectiva adotada para formulação da estratégia competitiva da pequena empresa, as forças de mercado, há um número maior de riscos estratégicos, porém que causam menor impacto e apresentam menor probabilidade de ocorrência na pequena empresa estudada.

Palavras-chave: Pequena empresa. Competências dinâmicas. Forças de mercado. Riscos estratégicos.

\section{Abstract}

The competitive advantage of small business can be created by different perspectives, among which are evidenced strategies based on market forces and strategies based on specific features and capabilities of the organization. In small companies it is noted that there is greater emphasis on creating strategies based on market forces, even though the use of this perspective, can be reduced the company's competitiveness. Therefore, the objective of this 
study is to understand how they arise and what are the risks from the formulation of competitive strategy in small business from the perspective of the operation of market forces rather than the dynamic capability perspective. To this end, we used a case study in a small retail company in Curitiba, which allowed the verification of the design of strategies formulated in small business and the risks associated with them. In the first phase of the study, data were collected through interviews and observation, and analyzed according to content analysis. For verification of strategic risks was developed a cognitive map to identify risks and apply an adaptation of the model Brasiliano (2006) for measurement and risk analysis. It was found that on the main perspective adopted for the formulation of the small company's competitive strategy, market forces, there are a greater number of strategic risks, but they cause less impact and are less likely to occur in the small business study.

Keywords: Small business. Capability dynamics. Market forces. Strategic risks.

\section{Introdução}

A criação da vantagem competitiva e estratégias baseadas na perspectiva da criação de competências que sejam sustentáveis no negócio vêm sendo amplamente discutidas no meio acadêmico. Há influência direta nos níveis de desempenho das organizações em virtude da capacidade de uma organização a se adaptar às forças externa e gerar e manter competências técnico-organizacionais que sejam dinâmicas e, portanto, adaptáveis no cenário empresarial de constantes mudanças (ASSUMPÇÃO; FIGUEIREDO, 2007).

Para Prahalad e Hamel (1995), as tendências, as premissas e as pressuposições sobre a estrutura de seu ramo de atividade, assim como clientes, concorrentes e valores envolvidos, devem ser chaves para o pensamento estratégico. Esse pensamento é proveniente do próprio ambiente empresarial e das pessoas envolvidas na organização. Porém, quando há rápidas mudanças no ambiente, as crenças podem se transformar em uma ameaça à sobrevivência de qualquer empresa.

As competências dinâmicas, importantes para todos os tipos de organização, devem ser enfatizadas em organizações que estão inseridas em ambiente estritamente competitivo. Entretanto, há pouca ênfase na formulação estratégica com base na perspectiva de competências dinâmicas da organização, especificadamente em pequenas empresas. A estratégia competitiva de pequenas empresas muitas vezes é fundamentada apenas na perspectiva das forças de mercado (PORTER, 1980), a fim de equivaler padrões já estabelecidos.

Portanto, se faz necessário entender como se formam os riscos estratégicos provenientes da formulação da estratégia competitiva da pequena empresa sob a perspectiva das forças de mercado em detrimento da perspectiva baseada nas competências dinâmicas da organização, e qual é a probabilidade de sua concretização e o impacto causado por eles na pequena empresa.

O objetivo deste estudo é entender como surgem e quais são os riscos provenientes da formulação da estratégia competitiva na pequena empresa sob a perspectiva da exploração das forças de mercado em detrimento da perspectiva das competências dinâmicas. Como objetivos específicos, o estudo pretende identificar os possíveis fatores de riscos estratégicos de uma pequena organização, avaliar o grau de probabilidade dos riscos e mensurar a relevância do impacto dos riscos nas atividades e na imagem da organização. Para tanto, a pesquisa realizada em uma pequena empresa de varejo de Curitiba estrutura um mapeamento cognitivo do processo de formulação de estratégia e mensura os riscos estratégicos por meio de uma proposição adaptada do método Brasiliano (2006) de análise de riscos.

\section{Referencial teórico-empírico}

0 referencial teórico-empírico descrito neste capítulo tem por objetivo fundamentar a construção do conhecimento proposto para embasar esta pesquisa por meio de conceitos que estão diretamente vinculados à definição e contextualização da formulação da estratégia competitiva na pequena empresa, criação de vantagem competitiva na pequena empresa e gerenciamento de riscos estratégicos.

\section{A formulação da estratégia competitiva na pequena empresa}

A estratégia não é definida de uma única forma (GIMENEZ, 1998; RUAS et al., 2005). Para Chandler 
(1962), a estratégia trata-se da determinação de objetivos de longo prazo e adequação de ferramentas e recursos para atingi-los. Para Andrews (1991), a estratégia é o padrão de objetivos, metas, políticas e planos a fim de delinear em que negócios a empresa vai competir e de que forma. Já Mintzberg (1988) afirma que a estratégia é o procedimento que permite à empresa adequar-se e estruturar-se de acordo com seu ambiente, formando um padrão na tomada de decisões organizacionais.

Deste modo, pode ser verificada a convergência nos conceitos, e a estratégia pode ser definida como um conjunto de diretrizes conscientemente deliberadas, ajustadas conforme objetivos estabelecidos, ambiente competitivo e recursos disponíveis, que orientam as decisões organizacionais (GIMENEZ et al., 1999, p. 4).

Entretanto, Porter (1985) afirma que a estratégia organizacional está baseada em ações ofensivas ou defensivas, a fim de criar uma posição favorável no setor. Para o autor, o paradigma tradicional da organização industrial se fundamenta na formulação da estratégia a partir das competências internas e avaliação do ambiente externo (estrutura de Learned, Christensen, Andrews e Guth, denominada LCAG).

Conforme a estrutura LCAG, a concepção da estratégia surge a partir da necessidade de ajudar a defender a empresa de eventos e decisões que possam gerar desordem ou desestruturação competitiva da empresa no seu ambiente. Isto possibilita que a formulação da estratégia seja um processo amplamente orientado a verificações das particularidades do ambiente interno e externo da empresa, dependentes das características competitivas do setor, dentro de uma sequência de passos lógicos e analíticos. Este fato inclui as incertezas do cenário empresarial que exigem a adequação das estratégias às novas realidades e ao ambiente de constantes mudanças.

As estratégias da empresa devem mudar (ou se adaptar) diante de novas oportunidades e ameaças no ambiente e mudar suas próprias competências e intenções estratégicas. Para tanto, a estratégia como processo enfatiza e auxilia a adaptação e renovação da estratégia (DOZ; CHAKRAVARTHY, 1992). A estratégia como processo estabelece como a estratégia em si pode ser viabilizada. Trata de quais métodos e procedimentos podem ser realizados para possibilitar a concretização da estratégia pensada.

Para tanto, conforme Sull (2006), a antecipação estratégica e a agilidade organizacional auxiliam para que a empresa possa melhorar suas capacidades a fim de adaptar-se a ameaças e oportunidades que surjam. A antecipação estratégica é o processo cognitivo capaz de identificar os primeiros sinais de advertências, visualizar ligação entre acontecimentos não relacionados diretamente, além de identificar variáveis decisivas para a solução ou minimização de eventuais problemas. A agilidade organizacional se refere à flexibilidade da empresa em assumir novas atividades ou mudanças de modo a otimizar os objetivos da empresa. A combinação destes fatores permite a formulação de estratégias orientadas ao gerenciamento de riscos estratégicos e possibilita 0 surgimento de vantagens competitivas para o negócio (SLYWOTZKY, 2007).

\section{A criação de vantagem competitiva}

na pequena empresa

A visão do mundo Shumpeteriano, o qual tem o modelo de competição baseado na inovação, preço, performance, retornos financeiros e o processo de construção destrutiva, até hoje se faz presente em muitas organizações. Todavia, ainda hoje a questão fundamental discutida em muitos trabalhos acadêmicos e tema de estrita relevância para o mundo empresarial é como criar e manter a vantagem competitiva.

Teece et al. (1997) e Lima, Castro e Machado (2007) abordam a questão da evolução e complementação entre paradigmas da criação de vantagem competitiva. Existem duas vertentes para a formulação da estratégia competitiva: a exploração de forças do ambiente e a exploração da eficiência da empresa. A abordagem das forças competitivas (PORTER, 1980), que estabelece o fluxo de informações conforme estrutura, conduta estratégica e performance, e do conflito estratégico, Shapiro (1989 apud TEECE et al., 1997), que enfatiza a Teoria dos Jogos, formam o modelo de exploração das forças competitivas conforme verificação do ambiente externo da empresa. Já o modelo estratégico que visa à eficiência empresarial baseia-se no foco da visão baseada em recursos (BARNEY, 1991) e na abordagem das competências da organização (TEECE, 1988; PRAHALAD; HAMEL, 1990), ou seja, prioriza o ambiente interno e suas capacidades técnico-organizacionais. Essas correntes de pensamento podem ser consideradas tanto concorrentes quanto complementares. Entretanto, todas elas culminam no desenvolvimento de elementos e 
características particulares da empresa que possam se tornar fonte de vantagem competitiva.

Porter (1980) afirma que a vantagem competitiva da empresa pode ser obtida por meio da elaboração de uma estrutura voltada a prevenir e contra-atacar cinco forças competitivas baseadas nas barreiras de entrada, poder de negociação dos compradores, poder de negociação dos fornecedores, ameaça de produtos substitutos e intensidade da rivalidade entre empresas concorrentes.

Acerca da abordagem do conflito estratégico, Shapiro (1989) argumenta que a vantagem competitiva da empresa pode ser obtida agindo e reagindo conforme as estratégias propostas pelos concorrentes, possibilitando ver o efeito competitivo de acordo com sua efetividade.

Já para Barney (1991, p. 99), a vantagem competitiva da empresa provém da visão baseada em recursos, teoria a qual afirma que as empresas obtêm vantagem competitiva sustentada quando implementam estratégias que exploram suas forças internas, respondendo a oportunidades do ambiente, enquanto neutralizam ameaças externas e evitam fraquezas internas.

No entanto, apesar da perspectiva baseada em recursos não esclarecer como as organizações devem criar, desenvolver e manter suas vantagens competitivas (PETERAF, 1993), descreve que existem algumas condições para obtenção da vantagem competitiva e melhor desempenho no mercado. Dão a heterogeneidade dos recursos existentes na empresa, evitar que os custos de obtenção dos recursos eliminem as rendas da empresa (limites ex-ante à concorrência), evitar que a fonte de renda da empresa possa ser compartilhada pelos concorrentes (imposição de limites ex-post) e assegurar de forma consistente que os recursos permaneçam na empresa.

Prahalad e Hamel (1995) e Barney (1991), quando se referem aos recursos como fonte de vantagem competitiva, asseguram que, para ser considerada uma competência essencial da organização, uma habilidade precisa ser percebida pelo cliente como um valor adicional, deve ser singular, ou seja, possuir diferenciação entre os concorrentes, além de ter capacidade de expansão, pois constituirá a base para a entrada em novos mercados.

A competência essencial também é considerada uma fonte de vantagem competitiva da empresa por emergir com o tempo, aumentando sua relevância e aprimorando sua efetividade conforme sua constante utilização, por meio de um processo organizacional para acumular e aprender a dispor os diferentes recursos e capacidades (CORRÊA; CORRÊA, 2004). Deste modo, possibilita agregar valor ímpar aos negócios e possibilita o desempenho dessa competência de modo superior aos concorrentes, ou seja, acima da média conquistada pelo mercado.

Com essas mudanças e inconstância no cenário de negócios, as empresas devem criar vantagem competitiva baseadas em uma abordagem a qual priorize a sustentabilidade de diferenciais competitivos diante de condições desfavoráveis. Para tanto, surgem, segundo Teece et al. (1997), as competências dinâmicas. Apesar da variedade de competências destacadas na literatura (RUAS et al., 2005), como é o caso da competência distintiva (FIOL, 1991), das competências essenciais (PRAHALAD; HAMEL, 1990), e das competências específicas da organização (STALK; EVANS; SHULMAN, 1992), as competências dinâmicas se tornam uma questão central da estratégia empresarial pelo fato de estarem relacionadas diretamente ao ambiente e suas constantes mudanças.

As competências dinâmicas se referem à abordagem que identifica capacidades específicas que podem ser fonte de vantagem e explora a existência de competências as quais possam superar mudanças ambientais (TEECE et al., 1997). 0 termo "dinâmicas" destaca-se pela possibilidade de renovação e alterações determinadas pelo ambiente de mudanças.

Mesmo com toda a "dinâmica" ambiental referida, muitas pequenas empresas ainda adquirem a competitividade no seu setor tentando apenas reagir ou se adequar aos níveis praticados no mercado. Isto é, a competitividade entre as pequenas empresas não é vista como uma vantagem diferencial, mas como uma forma de serem sustentáveis no mercado e se assimilar a concorrência. Este fato desencadeia diversos fatores que podem prejudicar toda a trajetória estratégica da empresa: são os riscos estratégicos. Os riscos estratégicos, fundamentados no processo de implementação da estratégia, podem refletir diretamente em níveis do desempenho da empresa, e, por este fato, são considerados de extrema importância na avaliação e planejamento da estratégia.

\section{Riscos estratégicos}

Os riscos estratégicos são as tendências e eventos externos capazes de afetar a trajetória de crescimento 
de uma empresa (SLYWOTZKY, 2007). Todavia, os riscos estratégicos, como cita Slywotzky (2004, 2007), não devem ser vistos apenas como provenientes de fatos e eventos externos ao mundo corporativo. Os riscos estratégicos surgem geralmente na implementação de estratégias, julgadas pelos administradores que podem ser eficazes para alavancagem dos negócios. Deste modo, perigos na implementação da estratégia também podem estar ligados ao ambiente interno da empresa, com ou sem influência direta dos eventos externos (CHATERJEE, 2005).

0 autor afirma que um ponto-chave é a questão de focar em uma perspectiva de fora para dentro da empresa, analisando questões chaves do negócio no seu ambiente externo, como as ações que se refletem fora da empresa, ou seja, na percepção de seus públi$\cos$, e que poderão refletir em risco para o ambiente interno da empresa. Esses riscos são concernentes à demanda, à competitividade e à competência, conforme afirma Chatterjee (2005).

Para Chatterjee (2005), o risco de demanda se refere ao processo pelo qual o mercado não está disposto a aceitar a proposta de valor oferecida pela empresa, ou, por outro lado, que a demanda se torne superior à esperada e à suportada pela empresa (CHATERJEE, 2005). Slywotzky (2007) se refere a esse risco como o risco do consumidor, o qual pode mudar suas prioridades e preferências rapidamente, conforme tendências e outros fenômenos. Deste modo, a empresa pode se tornar vulnerável aos concorrentes que podem captar o seu mercado, caso não exista capacidade de adaptação por parte da empresa. Ou seja, "a incapacidade de lidar bem com uma demanda inesperada pode deixar a empresa vulnerável ao risco competitivo" (CHATTERJEE, 2005, p. 26).

$\mathrm{Na}$ definição da estratégia competitiva, as empresas podem optar por diferenciar os seus produtos da concorrência. A inovação é um fator crítico de competitividade que normalmente está associada a maiores margens e acarreta, no entanto, riscos. 0 risco competitivo, para Chaterjee (2005), trata-se da incapacidade de a empresa apresentar diferenciais diante da concorrência.

As empresas, na maioria das vezes, precisam optar pelos dois principais riscos da estratégia: o risco de demanda ou o risco competitivo. As empresas que tentam inovar em determinados quesitos, deixando para trás a concorrência, podem sofrer com questões relacionadas à grande procura da novidade e não suportar administrar o diferencial proposto. Por outro lado, as empresas que se focam em administrar a procurar por seus produtos ou serviços, com aumento da equipe, com esforços de vendas e outras táticas, correm os riscos de se igualar aos negócios da mesma categoria.

A competência da empresa é especificada por Chaterjee (2005, p. 52) como "conjuntos interligados de atividades que atingem um objetivo central específico". Ela pode se relacionar com um risco para a organização quando as estratégias delineadas não permeiam de forma adequada as competências essenciais da empresa, ou quando não existe um objetivo claro central a ser perseguido. Assim, o crescimento desordenado da empresa e a diversificação em negócios não relacionados aos objetivos da organização podem se tornar sérios perigos. Para Chaterjee (2005, p. 125), "um dos maiores problemas de uma empresa de sucesso é imaginar como crescer fora do nicho em que obteve sucesso", revelando a questão da extendabilidade da competência essencial (CORRÊA; CORRÊA, 2004). Tanto na adaptação da empresa em mercados já existentes ou na formação de um novo contexto de mercado, a empresa poderá se deparar com os dois principais tipos de risco: competitivo e de demanda.

Beer e Eisenstat (2000) abordam a questão de seis riscos na implementação de estratégias pela ótica de dentro para fora da empresa. Citados com muita frequência em outros estudos, os assassinos silenciosos como os autores se referem - são os seis principais riscos que podem bloquear ou mudar totalmente o rumo e o sucesso de implementação de estratégias empresariais: estilo gerencial ineficaz, falta de clareza na estratégia e prioridades conflitantes, líderes ineficazes, comunicação vertical inadequada, coordenação inadequada entre funções ou divisões dentro da empresa, além de falta de habilidade de desenvolvimento de recursos humanos que ocupam escalões inferiores.

A esse respeito, Gofee e Jones (2006) relatam que os líderes devem estar aptos a observar, compreender e responder a situações de incertezas. A resposta dada pelo líder auxilia a modelagem de um modelo de prevenção e gerenciamento do risco a ser adotado por seus seguidores. Essa percepção provém de uma ruptura entre a estagnação da empresa para a visualização de possíveis situações negativas no contexto da empresa (ATKINSON, 2007).

Entretanto, no ambiente externo da empresa, sérios perigos podem fazer fracassar a estratégia da 
empresa. Riscos da adaptação de novos projetos, erosão e perda de credibilidade da marca, risco concorrencial, mudança no conceito de negócios, mudanças tecnológicas, arrocho em margens do setor, mudanças nas prioridades dos clientes, mudanças drásticas na economia e a estagnação do mercado são os principais vilões da estratégia empresarial (SLYWOTZKY, 2004, 2007; SLYWOTZKY; DRIZK, 2005).

Muitas organizações olham para modelos de trabalho para responder e capitalizar perigos sociais e ambientais. A verificação de riscos pode ocasionar o surgimento de boas oportunidades do negócio, como afirmam Bekefi e Epstein (2008). Para os autores, ser capaz de identificar e gerenciar os riscos estratégicos pode se transformar em uma fonte de inovação e guiar o sucesso do mercado.

A esse respeito, Porter (1985) destaca que o paradigma tradicional da organização industrial baseia-se no estabelecimento da performance da empresa proveniente de estratégias ditadas pela estrutura do setor competitivo. Todavia, este fluxo da estratégia pode (e deve) ser alterado conforme a possibilidade da empresa adotar vantagens em sua performance, de forma superior que os concorrentes, e ditar as estratégias e estrutura do setor. Para culminar neste estágio, a estratégia da empresa e sua forma de gerar e manter a vantagem competitiva devem estar perfeitamente alinhadas com a estrutura organizacional.

Para Andrews (1991), a estratégia está intimamente ligada à estrutura, atuação e cultura organizacional, isto é, a estratégia pode ser considerada a espinha dorsal da organização, a qual permite alinhar todos os membros em uma só direção.

Pádua, Cazarini e Inamasu (2004) afirmam que os recursos organizacionais necessários à implementação de uma estratégia não devem ser apenas considerados como uma descrição da funcionalidade do sistema. Eles devem ser adequados conforme a estratégia e estrutura da empresa.

Nesse contexto, a modelagem organizacional facilita o entendimento do ambiente empresarial, além de ser uma atividade valiosa pela engenharia de requisitos (ALENCAR, 1999). O modelo organizacional é uma representação estrutural de atividades, processos, informações, recursos, comportamentos, objetivos e restrições das empresas. Esse modelo auxilia a compreensão das interações entre as organizações e as pessoas. 0 modelo também auxilia a adaptação e compreensão acerca das competências desenvolvidas pela organização.
Os funcionários, peças essenciais desse jogo, irão conduzir a estrutura da empresa ao estágio desejado. Para Prahalad e Hamel (1995), na ausência de desafios nitidamente definidos aos funcionários, eles ficam impotentes para contribuir com a competitividade, favorecendo o surgimento de riscos. Esta consciência torna-se fundamental, pois uma oportunidade de alinhamento da estratégia com o comportamento e atitude dos funcionários proporciona a capacidade e compromisso para com a organização, possibilitando resultados reais para a empresa, pois, como no jogo de xadrez, todas as peças são de extrema importância, uma vez que elas movimentam boa parte do jogo. Assim, qualquer movimento errado pode afetar toda a empresa.

\section{Metodologia da pesquisa}

\section{Caracterização da pesquisa}

A fim de entender como se formam os riscos estratégicos provenientes da formulação da estratégia competitiva da pequena empresa sob a perspectiva das forças de mercado em detrimento da perspectiva baseada nas competências dinâmicas da organização, e qual é a probabilidade de sua concretização e o impacto causado por eles na pequena empresa, esta pesquisa apresenta caráter exploratório e explicativo. 0 estudo se baseia na metodologia de indução, de forma qualitativa, com recorte transversal, utilizando como estratégia da pesquisa o estudo de caso.

0 estudo de caso será viabilizado, pois permite obter informações aprofundadas acerca do ambiente interno e externo, além de permitir o estudo de fenômenos sociais em sua totalidade, possibilitando identificar detalhes como estratégias, estrutura, acontecimentos, ciclo de vida, dentre outras situações da realidade (YIN, 2001). 0 estudo de caso possibilitará a identificação e a análise dos fatores de riscos estratégicos, por meio do mapeamento da formulação da estratégia. A unidade de análise será uma pequena empresa de varejo de Curitiba.

Para tanto serão abordadas as seguintes questões de pesquisa:

1) como é formulada a estratégia competitiva da pequena empresa?

2) como surgem e quais são os riscos estratégicos na formulação da estratégia competitiva 
da pequena empresa baseada na perspectiva de análise de ambiente externo e das forças de mercado?

3) como surgem e quais são os riscos estratégicos na formulação da estratégia competitiva da pequena empresa baseada na perspectiva de competências dinâmicas?

4) qual é a influência da estratégia baseada na perspectiva do ambiente externo e forças do mercado e das competências dinâmicas da pequena empresa na relevância do impacto e no grau de probabilidade dos riscos estratégicos?

\section{Coleta e tratamento dos dados}

Como técnicas da pesquisa foram realizadas entrevistas, observação participativa e aplicação de questionário estruturado. As entrevistas foram realizadas com os sócios da pequena empresa com roteiro de questões semiestruturadas. As observações, realizadas durante o período de três meses, permitiram identificar as formas de concepção das estratégias da pequena empresa. A observação realizada apresenta caráter participativo, pois há reconhecimento do pesquisador como integrante auxiliar na mediação da implementação das estratégias propostas.

O questionário, como técnica quantitativa do estudo de caso, foi realizado com o intuito de avaliar objetivamente a percepção dos sócios quanto aos riscos que podem surgir conforme os tipos de formulação da estratégia empregados. A metodologia utilizada para avaliação é baseada no método proposto por Brasiliano (2006). Este método possibilita a análise de modo qualitativo, definindo aspectos pertinentes a cada realidade organizacional, entretanto codifica os dados para análise de forma objetiva. Desta forma, os métodos utilizados para a coleta de dados permitiram a triangulação por meio de múltiplas fontes de evidências, permitindo resultados mais concretos acerca do tema.

\section{Contextualização do objeto de pesquisa}

Uma pequena empresa do varejo foi a base para o desenvolvimento desta pesquisa. A loja trabalha com a revenda de artigos para animais de estimação, como rações, produtos de higiene, brinquedos e acessórios variados, e também disponibiliza serviços veterinários e serviços de banho e tosa.
Fundada em 2002, possui uma vasta carteira de clientes e uma marca reconhecida no mercado deste ramo na cidade de Curitiba, além de um quadro de 8 funcionários, incluindo dois sócios que atuam diretamente nas atividades da empresa. Os sócios da empresa, um casal de classe média, idealizaram abrir a Pet Shop com o intuito de, além de manterem uma renda, fazerem o que mais gostam: cuidar de animais. A percepção de que eles fazem realmente o que gostam é constatada na qualidade do atendimento aos clientes, assim como na qualidade do atendimento aos cães e gatos.

Como objetivo, os sócios da pequena empresa esperam se tornar referência em Pets Shops da cidade, e para tanto priorizam ter em sua loja produtos e serviços que ofereçam qualidade a seus clientes. 0 conceito de "servir bem" é agregado de forma expressiva, principalmente nas formas de atendimento.

Possuem uma forma especial de se relacionar com os clientes e fornecedores e são atentos às novidades desse mercado. São preocupados com o ambiente interno de trabalho, fato este que pode ser visto em algumas situações de reuniões com os funcionários, simples paradas para o lanche, que eles mesmos preparavam para os funcionários, nos quais existe muita descontração. E, pelo fato de os sócios possuírem a preocupação no bom atendimento e no relacionamento com os clientes, eles se preocupam com o perfil específico dos funcionários que atuam na loja. Por isso existe uma prévia seleção dos candidatos a vagas.

Com os fornecedores e clientes mais próximos, eles mantêm um clima de amizade, simpatia e atenção, não apenas restrito ao lado comercial. A dedicação dos atendentes da empresa, percebida em algumas participações de negociações com fornecedores e no acompanhamento do atendimento a clientes relatados nas entrevistas, se faz presente no dia a dia da pequena empresa. Com este posicionamento, os sócios acreditam que conseguem manter um bom relacionamento com clientes, fornecedores e com os próprios funcionários, aumentando o reconhecimento e reforçando a imagem da loja, o que na opinião dos sócios vale tanto quanto a venda de seus produtos e seus serviços.

Este bom relacionamento permite surgirem oportunidades junto aos fornecedores, como facilidades de compra, melhor capacidade de negociação, auxílio em atividades e melhorias da empresa, como reformas que podem levar a marca do fornecedor, eventos, promoções e treinamentos para os funcionários. 
Outro ponto destacado, conforme o relacionamento mantido entre a pequena empresa e seus principais fornecedores, foi a possibilidade de interação às novidades do setor e informações, de forma ética, pertinentes à atuação de alguns concorrentes.

Entretanto, a percepção dos sócios quanto a atuação dos concorrentes não fica restrita apenas a verificar como eles estão se organizando no setor, mas também a forma como os concorrentes estão competindo no mercado. Verificam estratégias de exposição de produtos, preços, marcas fornecidas aos clientes, serviços prestados, atuação dos funcionários, processos e operações e questões referentes aos procedimentos de compra e venda de produtos. A partir desta análise realizada pelos sócios, eles formulam estratégias que sejam semelhantes, pois afirmam que utilizar estratégias que dão certo nos concorrentes e em outras organizações do setor, mesmo com as quais não têm contato direto, como fabricantes de rações, permite a eles terem maior possibilidade de sucesso.

\section{Diagnóstico do objeto de pesquisa}

Com os dados coletados foi observado que as estratégias da pequena empresa em questão são formuladas com base no benchmarking, ou seja, utilizam as estratégias que dão certo com os concorrentes ou com grandes organizações do setor. A utilização deste processo para a formulação da estratégia limitou a orientação da empresa diante de uma capacidade técnica específica da organização, os relacionamentos interpessoais e interorganizacionais, enfatizando a utilização da estratégia sob a ótica das forças de mercado. Portanto, diante da metodologia adotada para a concepção da estratégia, foram verificados riscos estratégicos principalmente com ênfase na abordagem da singularidade e competitividade de forma sustentável.

Conforme recomendação do método Brasiliano (2006) de análise de riscos, o qual se refere ao levantamento de riscos com base em critérios de suas causas e efeitos, foram mapeados alguns pontos de riscos da formulação estratégica da pequena empresa, com base na elaboração de um mapa cognitivo.

Os mapas cognitivos são representações, esquemas ou modelos mentais construídos pelos indivíduos, a partir das suas interações e aprendizagens em um domínio específico do seu ambiente, e que cumprem a função de dar sentido à realidade. A esse respeito os mapas cognitivos podem ser vistos como uma figura ou representação de análise de dados que auxilia na compreensão de aspectos particulares e seletivos, e elementos do pensamento.

Dentre as principais características dos mapas cognitivos estão a possibilidade da idealização do pensamento por meio de palavras, estrutura hierárquica, relação de causalidade e caráter bidimensional. A partir destas características, pode-se dizer que um mapa retrata alguém capaz de pensar sobre situações dentro do contexto de um simples sistema de valores hierárquicos que implicam cada valor em outro que, em última análise, implica um único valor superordenado. Assim, uma pessoa poderá ser julgada como cognitivamente simples e bem organizada em relação ao tema quando um mapa tem a forma de uma estrutura piramidal, ou com multiplicidade de conceitos e possivelmente objetivos conflitantes no caso de mapas que revelam um número relativamente grande de ideias chave. Desta forma, a partir do mapeamento cognitivo, podem ser verificadas, conforme a teoria, as possíveis fontes de riscos estratégicos, conforme Figura 1.

Os riscos estratégicos foram separados em seis grandes grupos. Esses grupos foram caracterizados pelo nível operacional e estratégico da instituição, e subdivididos com base em questões que podem interferir direta ou indiretamente nos fatores de risco, associados ao ambiente interno e ao ambiente externo da empresa (Quadro 1). Essa divisão de critérios propõe a verificação de riscos conforme o contexto da empresa, pessoas e processos (CAVALANTI; DIAS; BARROS, 2008). A separação de riscos estratégicos por grupos facilita a observação por setores da organização, além de possibilitar a adaptação dos fatores de riscos.

Os riscos que foram percebidos no mapeamento da formulação da estratégia competitiva da pequena empresa estudada tiveram maior incidência de riscos caracterizados como riscos competitivos (1) e riscos voltados aos relacionamentos que a pequena empresa mantém com seus públicos (2). 0 perigo relacionado à competitividade é evidenciado pela tentativa de a pequena empresa se posicionar de modo muito semelhante aos concorrentes, ou seja, a estratégia com base na perspectiva de verificar o ambiente externo e agir conforme as forças do ambiente deixam a empresa em um posicionamento competitivo de neutralidade externa (CORREA; CORREA, 2004).

Já os relacionamentos, conforme as estratégias verificadas da empresa, podem ser considerados como 


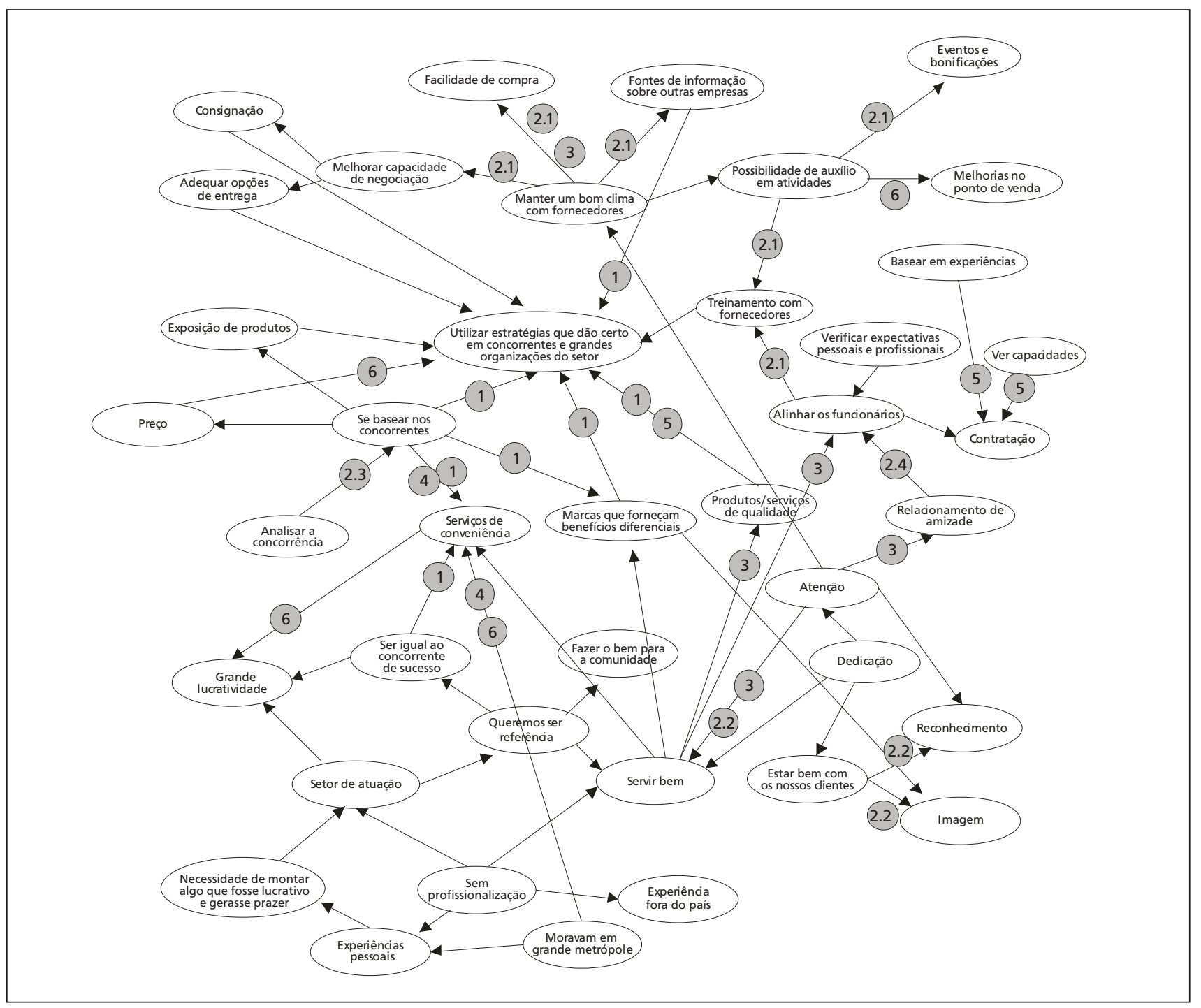

Figura 1 - Mapeamento dos riscos verificados no processo de formulação da estratégia da pequena empresa Fonte: Dados da pesquisa.

Quadro 1 - Grupos de riscos estratégicos verificados na pequena empresa

\begin{tabular}{|c|c|c|c|}
\hline & Riscos & & \\
\hline \multirow[t]{2}{*}{1.} & Competitivo & & \\
\hline & & 1. & Fornecedores \\
\hline \multirow{3}{*}{2.} & Relacionamento & 2. & Clientes \\
\hline & (competência específica) & 3. & Concorrentes \\
\hline & & 4. & Funcionários \\
\hline 3. & Demanda & & \\
\hline 4. & Novos Projetos & & \\
\hline 5. & Processos e Operações & & \\
\hline 6. & Financeiro & & \\
\hline
\end{tabular}

Fonte: Dados da pesquisa. uma competência não muito explorada, os quais também propiciam riscos agregados à percepção dos públicos. A partir destas duas formas verificadas na formulação da estratégia da pequena empresa, dando maior ênfase à perspectiva baseada em forças do mercado, podem ser analisados alguns pontos principais desses riscos de forma objetiva.

\section{Apresentação dos resultados}

O instrumento utilizado para a avaliação e análise de riscos estratégicos, tendo como base o contexto de uma pequena empresa do varejo, foi fundamentado no método Brasiliano de análise de riscos (2006). 
Apesar de o método Brasiliano (2006) apresentar características voltadas ao cálculo relativo a riscos corporativos em um contexto de empresas de segurança, o modelo apresenta uma metodologia de aplicação simplificada e que pode atribuir a possibilidade da observação objetiva dos dados.

A metodologia apresentada por Brasiliano (2006) consiste em mapear, de forma qualitativa e quantitativa, os riscos estratégicos conforme sua probabilidade de ocorrência e impacto financeiro. 0 risco estratégico, na visão do autor, é calculado conforme sua probabilidade de ocorrência versus o seu impacto, seja operacional ou financeiro.

0 diferencial da metodologia referenciada por Brasiliano (2006) é a possibilidade de calcular o Grau de Probabilidade do risco (GP), obtido por meio da multiplicação dos fatores do risco pelo seu critério de exposição. Os valores são obtidos por meio de notas subjetivas conforme um diagrama de causa e efeito, o qual permite desmembrar os fatores de risco.

Desta forma, a partir dos principais riscos mapeados na pequena empresa estudada, foi estruturado um questionário de investigação da percepção de riscos estratégicos. 0 questionário tem com finalidade verificar o ponto de vista das principais pessoas envolvidas na organização da forma mais objetiva possível.

0 questionário foi dividido em seis grupos de questões, os quais foram subdivididos conforme sua perspectiva de abordagem da estratégia. Diante da formulação da estratégia adotada sob a perspectiva baseada nas forças de mercado, os grupos identificados foram classificados em cinco grandes grupos de riscos (competitivo, demanda, novos projetos, processos e operações e financeiro), totalizando 17 abordagens genéricas de surgimento de riscos estratégicos. Já na perspectiva baseada nas competências dinâmicas da organização, foi observado um único grupo de riscos, relacionados à competência, mesmo que pouco enfatizada pela empresa, de criar e manter relacionamentos, totalizando 8 abordagens genéricas de surgimento de riscos estratégicos (Quadro 2).

No questionário, os respondentes avaliaram, em uma escala de Likert de 5 pontos, o nível de influência de cada risco nos fatores relacionados ao ambiente interno (Amb. Int), que considera aspectos relacionados a recursos humanos, política da empresa, recursos, capacidades e competências; e ambiente externo (Amb. Ext.), além de avaliarem a frequência e exposição dos riscos (E) e a relevância de impacto para a imagem, para as atividades e para as finanças da empresa.

Conforme dados coletados do questionário aplicado com os sócios, o risco estratégico foi calculado conforme a sua probabilidade de ocorrência (Prob.) e seu impacto causado. 0 grande diferencial adotado pela metodologia de Brasiliano (2006) é a possibilidade do cálculo do Grau de Probabilidade (GP) do Risco (média retirada da avaliação de cada item atribuído nos diferentes fatores de risco multiplicados pelo fator de exposição da organização ao risco). Já o impacto (Imp) proporcionado pela concretização do risco é calculado por meio da média ponderada entre os itens atribuídos a possíveis níveis de impacto (imagem, denominado Img., peso 4; e operacional, denominado Op., peso 2). Os níveis de impacto foram adaptados conforme os tipos de riscos mais relevantes para a pequena empresa estudada, neste caso, adaptando o modelo de

Quadro 2 - Estrutura do questionário de avaliação objetiva de riscos

\begin{tabular}{|c|c|c|c|c|c|c|c|c|}
\hline \multicolumn{6}{|c|}{ Fator de Risco } & Exposição ao risco & \multicolumn{2}{|c|}{ Relevância do Impacto } \\
\hline \multirow{7}{*}{ 을 } & \multirow{7}{*}{ Riscos } & \multicolumn{3}{|c|}{ Ambiente Interno } & \multicolumn{4}{|l|}{$\begin{array}{l}\text { Amb. } \\
\text { Externo }\end{array}$} \\
\hline & & Recursos & $\begin{array}{l}\text { Política } \\
\text { Empresa }\end{array}$ & $\mathrm{RH}$ & $\begin{array}{l}\text { Amb. } \\
\text { Externo }\end{array}$ & Frequência & $\begin{array}{l}\text { Imagem } \\
\text { (Peso 4) }\end{array}$ & $\begin{array}{l}\text { Operacional } \\
\text { (Peso 2) }\end{array}$ \\
\hline & & \multicolumn{4}{|c|}{ 5. Influencia muito } & 5. Constante & \multicolumn{2}{|c|}{ 5. Catastrófico } \\
\hline & & \multicolumn{4}{|c|}{ 4. Influencia } & 4. Frequente & \multicolumn{2}{|l|}{ 4. Crítico } \\
\hline & & \multicolumn{4}{|c|}{ 3. Influencia medianamente } & 3. Ocasional & \multicolumn{2}{|c|}{ 3. Moderado } \\
\hline & & \multicolumn{4}{|c|}{ 2. Influencia Levemente } & 2. Irregular & \multicolumn{2}{|l|}{ 2. Leve } \\
\hline & & \multicolumn{4}{|c|}{ 1. Influencia Muito Levemente } & 1. Remoto & \multicolumn{2}{|c|}{ 1. Desprezível } \\
\hline
\end{tabular}

Fonte: Dados da pesquisa. 
Brasiliano (2006), excluindo o impacto dos riscos no nível financeiro (peso 3) e nível legal (peso 2). Deste modo, com os dados coletados podem ser verificados os resultados apresentados no Quadro 3.

Conforme classificação de Brasiliano (2006), o instrumento de avaliação de riscos estratégicos aplicado na pequena empresa apresentou os resultados que podem ser vistos no Quadro 4.
O impacto proporcionado pela concretização do risco é calculado por meio da média ponderada entre os itens atribuídos a possíveis níveis de impacto (imagem, peso 4, e operacional, peso 2). 0 resultado pode ser verificado conforme o nível de criticidade.

$\mathrm{Na}$ matriz apresentada (Quadro 5), os riscos com maior probabilidade de ocorrência, sendo considerados com uma probabilidade muita alta de se

Quadro 3 - Resultados dos dados coletados

\begin{tabular}{|c|c|c|c|c|c|c|c|c|c|c|}
\hline & \multirow[t]{3}{*}{ Risco } & \multicolumn{2}{|c|}{ Fator de Risco } & \multirow[t]{2}{*}{ FR } & \multirow{2}{*}{$\frac{\operatorname{Expos}(\mathrm{E})}{\mathrm{E}}$} & \multirow[t]{2}{*}{ GP } & \multirow[t]{2}{*}{ Prob } & \multicolumn{3}{|c|}{ Relevância do Impacto } \\
\hline & & $\begin{array}{l}\text { Amb. } \\
\text { Int. }\end{array}$ & $\begin{array}{l}\text { Amb. } \\
\text { Ext. }\end{array}$ & & & & & Img. & Op. & Imp. \\
\hline \multicolumn{10}{|c|}{ Riscos Competitivos } & \\
\hline \multirow{4}{*}{1} & Não conseguir diferencial & 2 & 4 & 3 & 4 & 12 & $60 \%$ & 3 & 2 & 2,67 \\
\hline & $\begin{array}{l}\text { Produtos e serviços com o mes- } \\
\text { mo valor que os concorrentes }\end{array}$ & 3 & 4 & 3,5 & 3 & 10,5 & $53 \%$ & 4 & 2 & 3,33 \\
\hline & $\begin{array}{l}\text { Qualidade dos produtos e servi- } \\
\text { ços não percebida }\end{array}$ & 4 & 5 & 4,5 & 3 & 13,5 & $68 \%$ & 2 & 3 & 2,33 \\
\hline & $\begin{array}{l}\text { Mesmo serviços de conveniência } \\
\text { que os concorrentes }\end{array}$ & 1 & 4 & 2,5 & 3 & 7,5 & $38 \%$ & 3 & 1 & 2,33 \\
\hline \multicolumn{11}{|c|}{ Riscos de Relacionamento (competência) } \\
\hline \multirow{8}{*}{2} & Rompimento de contratos & 4 & 4 & 4 & 1 & 4 & $20 \%$ & 1 & 4 & 2,00 \\
\hline & Dificuldade de negociações & 4 & 5 & 4,5 & 3 & 13,5 & $68 \%$ & 1 & 2 & 1,33 \\
\hline & $\begin{array}{l}\text { Dificuldade de troca de infor- } \\
\text { mações }\end{array}$ & 3 & 2 & 2,5 & 2 & 5 & $25 \%$ & 1 & 3 & 1,67 \\
\hline & Dependência de fornecedores & 1 & 2 & 1,5 & 5 & 7,5 & $38 \%$ & 4 & 5 & 4,33 \\
\hline & Dependência de poucos clientes & 4 & 3 & 3,5 & 3 & 10,5 & $53 \%$ & 4 & 4 & 4,00 \\
\hline & $\begin{array}{l}\text { Imagem, reconhecimento e satis- } \\
\text { fação dos clientes afetada pelo } \\
\text { relacionamento }\end{array}$ & 4 & 5 & 4,5 & 1 & 4,5 & $23 \%$ & 5 & 3 & 4,33 \\
\hline & $\begin{array}{l}\text { Rendimento e motivação dos } \\
\text { funcionários }\end{array}$ & 5 & 4 & 4,5 & 3 & 13,5 & $68 \%$ & 2 & 4 & 2,67 \\
\hline & $\begin{array}{l}\text { Relacionamento mantido com } \\
\text { concorrentes }\end{array}$ & 3 & 3 & 3 & 4 & 12 & $60 \%$ & 4 & 2 & 3,33 \\
\hline \multicolumn{11}{|c|}{ Riscos de Demanda } \\
\hline \multirow{5}{*}{3} & $\begin{array}{l}\text { Diminuir atenção fornecida aos } \\
\text { clientes }\end{array}$ & 2 & 5 & 3,5 & 3 & 10,5 & $53 \%$ & 3 & 1 & 2,33 \\
\hline & $\begin{array}{l}\text { Proporcionar baixa qualidade do } \\
\text { atendimento }\end{array}$ & 3 & 5 & 4 & 1 & 4 & $20 \%$ & 5 & 2 & 4,00 \\
\hline & $\begin{array}{l}\text { Relacionamento de amizade não } \\
\text { ser mais percebido }\end{array}$ & 1 & 4 & 2,5 & 2 & 5 & $25 \%$ & 3 & 1 & 2,33 \\
\hline & $\begin{array}{l}\text { Alinhamento das estratégias de } \\
\text { forma adequada }\end{array}$ & 3 & 2 & 2,5 & 3 & 7,5 & $38 \%$ & 3 & 3 & 3,00 \\
\hline & Diminuir o poder de negociação & 4 & 3 & 3,5 & 2 & 7 & $35 \%$ & 1 & 2 & 1,33 \\
\hline
\end{tabular}


Quadro 3 - Resultados dos dados coletados

(conclusão)

\begin{tabular}{|c|c|c|c|c|c|c|c|c|c|c|}
\hline & Risco & Fato & $5 \mathrm{co}$ & FR & $\operatorname{Expos}(E)$ & GP & Prob & \multicolumn{3}{|c|}{ Relevância do Impacto } \\
\hline \multicolumn{11}{|c|}{ Riscos de Novos Projetos } \\
\hline \multirow[b]{2}{*}{4} & Serviços desconectados & 5 & 1 & 3 & 3 & 9 & $45 \%$ & 3 & 3 & 3,00 \\
\hline & $\begin{array}{l}\text { Novos projetos baseados nos } \\
\text { concorrentes }\end{array}$ & 3 & 4 & 3,5 & 1 & 3,5 & $18 \%$ & 3 & 3 & 3,00 \\
\hline \multicolumn{11}{|c|}{ Riscos relacionados a Processos e Operações } \\
\hline \multirow{2}{*}{5} & $\begin{array}{l}\text { Estratégias inadequadas ao am- } \\
\text { biente operacional da empresa }\end{array}$ & 3 & 4 & 3,5 & 2 & 7 & $35 \%$ & 4 & 5 & 4,33 \\
\hline & $\begin{array}{l}\text { Fornecimento de produtos e } \\
\text { serviços }\end{array}$ & 4 & 5 & 4,5 & 2 & 9 & $45 \%$ & 2 & 3 & 2,33 \\
\hline \multicolumn{11}{|c|}{ Riscos Financeiros } \\
\hline \multirow{4}{*}{6} & Preços baseados nos concorrentes & 4 & 3 & 3,5 & 1 & 3,5 & $18 \%$ & 1 & 1 & 1,00 \\
\hline & $\begin{array}{l}\text { Serviços de conveniência se tor- } \\
\text { narem o foco da empresa }\end{array}$ & 3 & 5 & 4 & 1 & 4 & $20 \%$ & 2 & 3 & 2,33 \\
\hline & $\begin{array}{l}\text { Dependência do auxílio de } \\
\text { terceiros }\end{array}$ & 4 & 1 & 2,5 & 3 & 7,5 & $38 \%$ & 2 & 4 & 2,67 \\
\hline & $\begin{array}{l}\text { Novos projetos baseados nos } \\
\text { concorrentes não contribuírem } \\
\text { para a lucratividade para a } \\
\text { empresa }\end{array}$ & 5 & 3 & 4 & 2 & 8 & $40 \%$ & 1 & 4 & 2,00 \\
\hline
\end{tabular}

Fonte: Dados da pesquisa.

Quadro 4 - Grau de Probabilidade de ocorrência do risco estratégico

\begin{tabular}{clc}
\hline Escala & Nível de Probabilidade & Probabilidade \\
\hline $1-5$ & Baixa & $4-20 \%$ \\
$5,01-10$ & Média & $20,4 \%-40 \%$ \\
$10,01-15$ & Alta & $40,4 \%-60 \%$ \\
$15,01-20$ & Muito Alta & $60,4 \%-80 \%$ \\
$20,01-25$ & Elevada & $80,4 \%-100 \%$ \\
\hline
\end{tabular}

Fonte: BRASILIANO, 2006, p. 55.

concretizarem, são referentes à qualidade dos produtos e serviços não ser percebida diante da concorrência (risco de demanda), à dificuldade de negociações, se a qualidade do relacionamento mantido com fornecedores for percebido por eles com níveis mais baixos que o habitual e ao fato do rendimento dos funcionários ser prejudicado, evidenciados por baixa motivação e distanciamento dos objetivos da empresa, se a qualidade do relacionamento mantido com os funcionários for percebida com níveis mais baixos que o habitual (risco de competência). Na pesquisa não foram revelados riscos com probabilidade muito elevada de se concretizarem. Entretanto, os riscos com o nível mais baixo de probabilidade de ocorrência são referentes aos preços praticados se fugirem da estratégia financeira da empresa, por se basear nos concorrentes (risco financeiro), novos projetos baseados nos concorrentes e que fujam da realidade dos clientes (risco de novos projetos), cair a qualidade do atendimento e dos serviços prestados com o aumento da demanda (risco de demanda) e rompimento de contratos por parte dos fornecedores (risco de competência/relacionamentos).

Já o impacto dos riscos estratégicos pode ser classificado em sua maioria como riscos marginais, ou seja, aqueles que apresentam baixa relevância de impacto tanto para as atividades quanto para a imagem da empresa. Apenas os riscos relacionados a ficar muito dependente de poucos clientes, de fornecedores para atividades internas e ter a imagem, reconhecimento e satisfação dos clientes afetada, se a 
qualidade do relacionamento mantido for percebida por eles com níveis mais baixos que o habitual (riscos de competência), além de cair a qualidade do atendimento e dos serviços prestados com o aumento da demanda (risco de demanda) e utilizar estratégias inadequadas ao ambiente operacional da empresa (risco relacionado a processos e operações).

Quadro 5 - Nível de criticidade dos riscos estratégicos

\begin{tabular}{llll}
\hline Nível de Criticidade & & De & Até \\
\hline Catastrófico & 4 & 4,00 & 5,00 \\
Crítico & 3 & 3,00 & 3,99 \\
Marginal & 2 & 2,00 & 2,99 \\
Desprezível & 1 & 1,00 & 1,99 \\
\hline
\end{tabular}

Fonte: BRASILIANO, 2006, p. 82.

\section{Discussão}

Os riscos estratégicos verificados nesta pesquisa, referentes a uma pequena empresa de varejo, conforme as duas perspectivas distintas de formulação de estratégias competitivas (forças de mercado e competências dinâmicas da organização), enfatizaram a incidência de maior probabilidade de riscos se concretizarem nas estratégias baseadas nas competências dinâmicas da organização.

Apesar de toda a discussão existente na literatura referente à criação e sustentabilidade da vantagem competitiva com base em competências as quais possam ser adaptadas a mudanças do cenário empresarial e possibilite o aumento de vantagem sobre os concorrentes, apresentando maior singularidade, possibilidade de expansão para novos negócios e valor para os clientes (TEECE et al., 1997; PRAHALAD; HAMEL, 1995; BARNEY, 1991), esta visão conotou maior probabilidade de ocorrência de riscos na pequena empresa estudada. Com base na média da probabilidade de concretização dos riscos (44\%, contra $38 \%$ dos riscos baseados nas forças de mercado), as competências dinâmicas da empresa se mostraram também mais perigosas à estratégia competitiva, embora não mais prejudiciais.

A esse respeito, Chatterjee (2005) afirma que, ao contrário de fugir dos riscos, o ideal é se basear no retorno ao evitá-lo. Portanto, o autor aponta duas dimensões para evitar esses riscos: a clareza e a escolha. A clareza se refere a identificar exatamente onde os riscos se encontram. Já a escolha trata-se da identificação de um maior número de opções de maneiras de se evitar os riscos do que os concorrentes. "Se a sua empresa se tornar muito hábil em evitar os riscos e, ao mesmo tempo, mantiver a maioria dos retornos, ela será mais lucrativa no longo prazo" (CHATERJEE, 2005, p. 24).

Com a competência dinâmica da organização focada na criação e na manutenção de relacionamento tanto com fornecedores quanto com seus clientes e funcionários, a pequena empresa do varejo consegue atribuir vantagens competitivas, mesmo diante dos riscos que podem surgir. Isso prova que a afirmação de Chatterjee (2005) e Slywotzky (2007), de que quanto maior o risco maior é o retorno e a competitividade, pode estar certa de fato.

0 impacto para a imagem e para as atividades da pequena empresa causado pelos riscos provenientes por esta perspectiva também é maior em sua média acerca da percepção dos sócios.

Já sob a ótica da estratégia baseada em perspectivas de combater as forças do mercado (PORTER, 1980), a qual é a utilizada com maior ênfase pela pequena empresa, os riscos estratégicos são mais amenos quanto ao impacto causado e quanto a sua probabilidade de ocorrência. Não apresentando grandes diferenças substanciais, mas de forma objetiva, como as considerações apresentadas pela adaptação do modelo de mensuração de riscos de Brasiliano (2006), apresentam divergências quanto ao posicionamento diante dos riscos estratégicos. A competitividade fica afetada de modo substancial em face da ausência de diferenciais competitivos diante da concorrência e pelo fato de se basearem nos aspectos chaves de estratégias utilizadas pela concorrência. No quesito de riscos relacionados à demanda, também são afetados, principalmente quanto à qualidade dos produtos oferecidos e dos serviços prestados. Este risco é o risco com maior probabilidade de ocorrência com o aumento da demanda e o que pode causar o maior impacto para a pequena empresa estudada.

\section{Considerações finais, recomendações e limitações}

Embora o estudo não apresente caráter confirmatório, por ser baseado em um estudo de caso em uma pequena empresa de varejo, ou seja, não pode 
ser generalizado para outras empresas, mesmo que de atividades e cenários semelhantes, por apresentar diversidade nas situações e atividades da organização, o estudo permitiu revelar que nem sempre a alternativa que apresente maior possibilidade de competitividade frente ao mercado reflita ausência de ou menores riscos estratégicos.

Embora este estudo apresente limitações como a falta de totalidade dos dados, apresentando riscos estratégicos apenas de modo genérico e com categorias abrangentes, e apenas um caso para retratar a questão da formulação de estratégias competitivas, ele apresentou algumas considerações relevantes.

No estudo de caso apresentado, pode ser observado que com a perspectiva estratégica adotada pela pequena empresa, focado mais nas forças de mercado, em detrimento da utilização das competências dinâmicas da organização, que neste caso também teria um certo foco para as forças de mercado por ser fundamentada em relacionamento com os seus públicos, os riscos estratégicos podem ser observados como menor probabilidade de ocorrência e menor impacto na imagem e nas atividades da empresa.

Entretanto, para verificar se há de fato o impacto direto do tipo de formulação da estratégia nos riscos formados, e se há impacto na competitividade da empresa, outros estudos devem ser realizados em outros tipos de negócios, considerando o setor como um todo, e aplicando o modelo de mensuração com caráter quantitativo e não apenas com caráter objetivo como realizado neste estudo.

\section{Referências}

ALENCAR, F. M. R. Mapeando a modelagem organizacional em especificações precisas. 1999. 304 f. Tese (Doutorado em Informática) - Universidade Federal de Pernambuco, Recife, 1999.

ANDREWS, K. R. The concept of corporate strategy. Homewood Illinois: Irwin, 1991.

ASSUMPÇÃO, J.; FIGUEIREDO, P. N. O papel das competências técnico-organizacionais na estratégia organizacional: evidências de cinco organizações não governamentais do Rio de Janeiro. Revista Análise, v. 8, n. 2, p. $158-172,2007$.

ATKINSON, W. A view from the top: the growing role of the chief risk officer. Risk Management, v. 54, n. 9, p. 24, 2007.
BARNEY, J. B. Firm resources and sustained competitive advantage. Journal of Management, v. 17, n. 1, p. 99-120, 1991.

BEER, M.; EISNSTAT, R. A. The silent killers of strategy implementation and learning. Sloan Management Review, v. 41 , n. 4 , p. 29-40, 2000.

BEKEFI, T.; EPSTEIN, M. J. Transforming social and environmental risks into opportunities. Strategic Finance, v. 89 , n. 9 , p. $42-47,2008$.

BRASILIANO, A. C. R. Análise de risco corporativo: método Brasiliano. São Paulo: Sicurezza, 2006.

CAVALANTI, V. F.; DIAS, R. A.; BARROS, R. T. O. M. de. Proposta de ferramenta de análise e controle de processos com foco em análise de riscos. Disponível em: $<$ http://www.vitorfc.com.br/Analise_processos_com_ foco_em_Riscos.pdf>. Acesso em: 10 set. 2008.

CHANDLER, A. D. Strategy and structure. Cambridge: MIT Press, 1962.

CHARTTEJEE, S. Estratégia à prova de falhas: como lucrar e crescer correndo riscos que outros evitam. Porto Alegre: Bookman, 2005.

CORRÊA, C. A.; CORRÊA, H. L. Administração da produção e operações. Porto Alegre: Bookman, 2004.

DOZ, Y.; CHAKRAVARTHY, B. S. Strategy process research: focusing on corporate self-renewal. Strategic Management Journal, v. 13, n. 51, p. 5-14, 1992.

FIOL, C. M. Managing culture as a competitive resource: an identity-based view of sustainable competitive advantage. Journal of Management, v. 17, n. 1, p. 191-211, 1991.

GIMENEZ, F. A. P. Escolhas estratégicas e estilo cognitivo: um estudo com pequenas empresas. Revista de Administração Contemporânea, v. 2, n. 1, p. 27-45, 1998.

GIMENEZ, F. A. P. et al. Estratégia em pequena empresas: uma aplicação do modelo Miles e Snow. Revista de Administração Contemporânea, v. 3, n. 2, p. 53-74, 1999.

GOFEE, R.; JONE, G. Ligar a antena, sintonizar e descobrir o caminho. Valor Econômico, abr. 2006.

LIMA, S. M. V.; CASTRO, A. M. G. de; MACHADO, M. dos S. Metodologia de avaliação de necessidade futura de competências essenciais em organizações de P\&D, com base no processo de geração do conhecimento. Rpot, v. 7, n. 2, p. 5-29, 2007. 
MINTZBERG, H. Strategy-making in three modes. In: QUINN, J. B.; MINTZBERG, H.; JAMES, R. A. (Ed.). Strategic process-concepts, contexts and cases. Englewood Cliffs, N.J.: Prentice-Hall, 1988.

PÁDUA, S. I. D. de; CAZARINI, E. W.; INAMASU, R. Y. Modelagem organizacional: captura dos requisitos organizacionais no desenvolvimento de sistemas de informação.

Gestão e Produção, v. 11, n. 2, p. 197-209, 2004.

PETERAF, M. A. The cornerstones of competitive advantage: a resouce-based view. Strategic Management Journal, v. 14, n. 3, p. 179-191, 1993.

PORTER, M. Competitive strategy. New York: Free Press, 1980.

PORTER, M. Competitive advantage. New York: Free Press, 1985.

PRAHALAD, C. K.; HAMEL, G. The core competencies of the corporation. Harvard Business Review, v. 68, n. 3, p. 79$91,1990$.

PRAHALAD, C. K.; HAMEL, G. Competindo pelo futuro: estratégias inovadoras para obter o controle do seu setor e criar os mercados de amanhã. Rio de Janeiro: Campus, 1995.

RUAS, R. et al. $\mathrm{O}$ Conceito de competência de $\mathrm{A}$ à $\mathrm{Z}$ - análise e revisão nas principais publicações nacionais entre 2000 e 2004. In: ASSOCIAÇÃO NACIONAL DE PÓS-GRADUAÇÃO E PESQUISA EM ADMINISTRAÇÃO, 29., 2005, Brasília. Anais...Brasília: EnANPAD, 2005.

SHAPIRO, C. The theory of business strategy. RAND Journal of Economics, v. 20, n. 1, p. 125-137, 1989.
SLYWOTZKY, A. J. Exploring the strategic risk frontier. Strategy \& Leadership, v. 32, n. 6, p. 11-19, 2004.

SLYWOTZKY, A. J. Do risco à oportunidade: as 7 estratégias para transformar ameaças em fatores de crescimento. Rio de Janeiro: Elsevier, 2007.

SLYWOTZKY, A. J.; DRZIK, J. Countering the biggest risk of all. Harvard Business Review, v. 83, n. 4, p. 78-88, 2005.

STALK, G.; EVANS, P.; SHULMAN, L. E. Competing on capabilities: the new rules of corporate strategy. Harvard Business Review, v. 70, n. 2, p. 57-69, 1992.

SULL, D. Decisões difíceis num mundo incerto. Valor Econômico, abr. 2006.

TEECE, D. J. Technological change and the nature of the firm. In: DOSI, G. et al. (Ed.). Technical changeand economic theory. New York: Pinter Publishers, 1988.

TEECE, D. et al. Dynamic capabilities and strategic management. Strategic Management Journal, v. 18, n. 7, p. 509533, 1997.

YIN, R. K. Estudo de caso: planejamento e métodos. Porto Alegre: Bookman, 2001.
Recebido: 20/07/2011

Received: 07/20/2011

Aprovado: 29/08/2011

Approved: 08/29/2011 